\title{
AS CONTRIBUIÇÕES DO MCT/ PUCRS NA FORMAÇÃO INTERDISCIPLINAR DE ESTUDANTES DE UM CURSO NORMAL
}

\author{
A. V. RODRIGUES ${ }^{1}$, C. C. SOUZA, J. B. ROCHA FILHO \\ ${ }^{1}$ Pontifícia Universidade Católica do Rio Grande do Sul \\ seduc.alvorividal@gmail.com*
}

Submetido 15/11/2016 - Aceito 03/12/2017

DOI: $10.15628 /$ holos.2017.5353

\begin{abstract}
RESUMO
Este trabalho teve como objetivo analisar as experiências vivenciadas por estudantes de um curso Normal durante uma visita ao Museu de Ciências e Tecnologia da Pontifícia Universidade Católica do Rio Grande do Sul (MCT/PUCRS), visando a antever as possíveis consequências em suas respectivas ações profissionais. $\mathrm{O}$ ambiente de interação e aprendizagem do Museu tornou possível organizar aulas envolvendo os experimentos e exposições visitadas, considerando esse local um espaço não formal de ensino, segundo a definição de Bianconi e Caruso (2005, p.20), que é “[...] qualquer tentativa educacional organizada e sistemática que, normalmente, se realiza fora dos quadros do sistema formal de ensino". Nesse sentido, utilizou-se
\end{abstract}

como instrumentos da pesquisa a elaboração de planos de aula com abordagem interdisciplinar, assim como as respostas a um questionário, por meio do qual foi possível conhecer as concepções das alunas sobre o planejamento de aulas e práticas pedagógicas. Para realização dessa análise foi utilizada a metodologia denominada Análise Fenomenológica Hermenêutica (AFH) (MEDEIROS, 2016), e a partir dela concluiu-se que as percepções prévias das estudantes foram pautadas por um caráter fragmentado, ou seja, disciplinar e multidisciplinar, enquanto que após a visita houve uma sensível tendência para a elaboração de planos de aulas com viés interdisciplinar, voltados para a pesquisa em sala de aula.

PALAVRAS-CHAVE: Museu Interativo, Formação Docente, Pesquisa em Sala de Aula.

\section{THE CONTRIBUTIONS OF MCT / PUCRS IN THE INTERDISCIPLINARY FORMATION OF STUDENTS OF A NORMAL COURSE}

\begin{abstract}
The objective of this study was to analyze the experiences of students at a high school course for preparing teachers during a visit to the Museum of Science and Technology of the Brazilian Pontifícia Universidade Católica do Rio Grande do Sul (MCT/PUCRS), in order to anticipate the possible consequences in their respective professional actions. The interaction and learning environment of the Museum made it possible to organize classes involving the experiments and exhibitions visited, considering this place a non-formal teaching space, according to the definition of Bianconi and Caruso (2005, p.20), which is "[...] any organized and systematic educational attempt that normally takes place outside the framework of the
\end{abstract}

formal education system". In this sense, the use of interdisciplinary classroom plans, as well as the answers to a questionnaire were used as tools of this research, through which it was possible to know their conceptions about the planning of classes and pedagogical practices. To carry out this analysis, we used the methodology called Análise Fenomenológica Hermenêutica (AFH) (MEDEIROS, 2016), and from it was concluded that the students' previous perceptions were based on a fragmented knowledges, like a collection of disciplinary and multidisciplinary information. After the visit, however, was a sensitive tendency for the elaboration of plans of classes with interdisciplinary bias, aimed at the research in the classroom.

KEYWORDS: Interactive Museum, Class Planning, Educating the search. 


\section{INTRODUÇÃO}

A educação, entendida como prática realizada em um espaço formal, muitas vezes ocorre por meio de ações docentes limitadas a atividades repetitivas e descontextualizadas. Utilizar a escola de forma limitante, porém, fragiliza os processos de ensino e de aprendizagem, tornando a escola pouco atrativa para os estudantes. Segundo o artigo no 53 do Estatuto da Criança e do Adolescente, "A criança e o adolescente têm direito à educação, visando ao pleno desenvolvimento de sua pessoa, preparo para o exercício da cidadania e qualificação para o trabalho [...]" (BRASIL, 1990), porém isso não garante que o aluno aprenda.

A escola tradicionalmente pratica aulas copiadas, em que o planejamento é construído a partir de um currículo disciplinar e descontextualizado. Nesse sentido, acredita-se que um ensino com abordagem interdisciplinar possa melhorar a aprendizagem, independentemente de sua área do conhecimento (DEMO, 2011). Portanto, nesta investigação foi proposta uma atividade de viés interdisciplinar, a partir da visitação a um espaço não formal interativo de ensino denominado Museu De Ciências e Tecnologia da Pontifícia Universidade Católica do Rio Grande do Sul (MCT/PUCRS). Essa visita teve como objetivo analisar as experiências vivenciadas pelas estudantes de um curso Normal de formação de professores para os anos iniciais, identificando em que medida essa visita poderia incentivar as futuras docentes a planejar aulas mais interativas e criativas, abandonando práticas pedagógicas mais tradicionais, ou seja, aulas expositivas dialogadas, por vezes cópias de outras, anteriores, que utilizam o livro didático como único instrumento.

A atividade fundamentou-se na elaboração de plano de aula com abordagem interdisciplinar, partindo das contribuições e percepções que a visita ao MCT/PUCRS proporcionou para oito alunas de um Curso Normal de uma instituição pública de ensino profissionalizante. Assim, a pesquisa avaliou a aderência das alunas à diversidade de estratégias do MCT/PUCRS, como contributo à prática pedagógica das estudantes.

Incluir atividades educacionais atrativas em um processo que some diferentes formas de ensinar enriquece a prática educativa do educador e inova os processos de ensino e de aprendizagem, unindo teoria e prática, estimulando, assim, um ensino contextualizado e interdisciplinar, contemplando diferentes áreas do conhecimento. O documento Salto para o Futuro (BRASIL, 2009) nos traz a relação entre museus e escolas, e afirma que os educadores devem rever o seu entendimento sobre a educação e sobre os processos educativos, pois "[...] sugere um ensino inovador e que explore, ainda mais, ambientes não formais de ensino, como o museu" (ibid.).

Assim, o futuro educador, imbuído de um espírito crítico e investigativo, proporcionado por atividades formativas que incluam espaços não-formais vê nas experimentações possibilidades inesgotáveis de tornar suas aulas mais bem elaboradas e significativas. Nesse sentido, esse educador contempla teoria e prática, facilitando os processos de ensino e de aprendizagem.

Em vista disso, este trabalho analisou as transformações na percepção dos participantes desta atividade a partir da elaboração de um plano de aula após a interação com o MCT/PUCRS. Além disso, também foram analisadas as respostas dos questionários aplicados antes e depois da visita ao mesmo. 
Conforme consta no site do MCT-PUCRS, o mesmo tem como missão gerar, preservar e difundir o conhecimento, possuindo numerosas coleções científicas, variados acervos de fósseis e exposições interativas. Ao se referir a museus, porém, é frequente que as pessoas tenham a imagem de um lugar de contemplação de coisas antigas, onde os visitantes são meros contempladores. Mas, não é assim em um museu interativo, e o MCT-PUCRS também tem a intenção de difundir a Ciência e o conhecimento, contribuindo para a alfabetização científica e tecnológica, assim como para popularização da ciência, tanto em sistemas educativos não formais quanto em sistema formais de ensino, promovendo assim a interação entre visitantes e experimentos. Segundo Castro, o papel do museu na sociedade seria:

Dentre as chamadas instituições de memória, o museu tem um papel ímpar na sociedade moderna como mediador entre o público e o acervo, e enquanto comunicador e produtor de discurso. A forma pela qual o público recebe o conteúdo e a mensagem de uma exposição museológica assegura e garante a legitimidade da função social do museu. (CASTRO, 2007, p.105)

O MCT/PUCRS, por sua vez, deu um passo além no que diz respeito à interação, que pode contribuir no aprendizado de estudantes e na formação de professores em geral na medida em que os experimentos interativos têm maior potencial de produzir significados, facilitando a aprendizagem. Portanto, o MCT/PUCRS proporciona aos professores oportunidades de formação que os levam a explorar atividades contextualizadas e participativas, visando à efetiva construção do conhecimento.

A ideia de museu, como se entende hoje, surgiu no contexto do Renascimento, e está associada à formação das coleções, ou seja, ao ato de acumular objetos, o que se considera um comportamento humano universal. Após a Primeira Guerra Mundial surgiram museus de ciências com papéis educativos e progressivamente mais dinâmicos, sendo procurados por públicos cada vez maiores (PIEDADE FILHO, 2009).

Os museus educativos também têm um papel de preservação da história, promovendo a educação, estando a serviço da sociedade, sem fins lucrativos, permanentemente a serviço da sociedade e seu desenvolvimento, aberto ao público, que adquire, conserva, pesquisa, comunica e exibe patrimônio tangível e intangível da humanidade e do seu ambiente para fins de educação, estudo e diversão (ICOM, 2007).

Portanto, em última instância a função de um museu é a valorização da dignidade humana, promoção da cidadania e a preservação do patrimônio cultural e ambiental. O MCT/PUCRS, segundo a museóloga Simone Monteiro, tem a função de transmitir o impacto real que a ciência tem na vida cotidiana presente por meio de exposições. A autora explica, também, que o MCT/PUCRS tem vida, porque tem ato político e técnicas que promovem a divulgação das exposições, permitindo que os visitantes interajam com os experimentos, fluindo, assim, o conhecimento.

\section{REVISÃO BIBLIOGRÁFICA}

\subsection{O MCT/PUCRS e a alfabetização científica}

As modificações sociais, tecnológicas e políticas do mundo de hoje atingem a educação, assim a sala de aula abrange novas realidades que a permeiam, modificando o ambiente escolar. 
Tais modificações devem ser acompanhadas pelo educador, em uma perspectiva de práticas inovadoras, indo ao encontro das novas realidades que o mundo globalizado apresenta.

Nesse contexto, o museu é como uma porta que se abre a oportunidades para conhecer desde o mundo novo até o mundo antigo, possibilitando a transição da informação ao conhecimento, por meio do aprendizado que vem do mundo externo para o mundo interno. Ocorrem, assim, diversas modificações dentro da sala de aula e, consequentemente, esta deixa de ser tradicional, ou seja, abandona a simples exposição de informações e referências a conhecimentos e assume um fluxo das informações, promovendo o conhecimento. Inverte-se a lógica, e as informações e o conhecimento são trazidos para dentro da sala de aula pelos alunos. Portanto, a escola deixa de ser um polo de disseminação de informações privilegiadas (CHASSOT, 2003).

O museu é considerado um espaço educacional não formal, onde os alunos e professores podem ampliar seus conhecimentos por meio das exposições e experimentos interativos, possibilitando um contato com o visitante. Essa interação e integração do ambiente/sujeito possibilita abrir as portas para o imaginário. No entanto, este deixa de ser um imaginário impossível, tornando-se um passado real que provoca a reflexão e a ação em prol de um ensino de maior qualidade.

Segundo as autoras Lara e Paula (2013), participar das experiências de visitante do museu é como acordar no imaginário e despertar sentimentos pela combinação entre o som e a iluminação, entre outras possibilidades que recriam algumas situações da vida cotidiana, ali retratadas. Essa imaginação cria asas para um novo conhecimento, partindo do que o sujeito sabe, ou seja, interseccionando as experiências da vida cotidiana com as vivenciadas no museu. $O$ novo conhecimento se enriquece na Ciência, e o professor deve saber fazer dessa Ciência um saber escolar. Dessa forma, contribuirá para a formação de sujeitos críticos, mas para isso o educador deverá incluir no seu currículo, componentes de aspectos sociais (CHASSOT, 2003). Nesse entendimento, é necessário que o educador saiba ler e compreender melhor as manifestações da natureza para explicar e ensinar as transformações que ocorrem no meio ambiente. Por isso " $A$ ciência pode ser considerada como uma linguagem construída pelos homens para explicar o nosso mundo" (Ibid., p.93).

O museu é uma fonte de inspiração tanto para os alunos como para o professor, e irradia conhecimentos e ajuda a compreender a linguagem científica sem descartar o conhecimento que já existe no sujeito, possibilitando a reconstrução do seu próprio conhecimento. A participação mais ativa dos alunos é impulsionada pelas emoções individuais de cada um, gerada na atividade livre que os experimentos dentro do MCT/PUCRS proporcionam. $\mathrm{O}$ indivíduo aprende por meio de experiências vivenciadas, sem romper com os princípios da aprendizagem.

É fundamental que se utilize o museu como um local de ensino e de aprendizagem no qual o educador promova situações nas quais o aluno pode conhecer o passado, o presente e imaginar o futuro, de modo que essa oportunidade construa novos conhecimentos para o indivíduo. É crítico que o professor tenha sempre um objetivo concreto e específico - um objeto de estudo determinado. Para isso, é fundamental que o educador faça um planejamento, incluindo uma prévisita no local a ser explorado, nesse caso, o MCT/PUCRS. 


\title{
2.2 O planejamento docente contemplando espaços não formais de ensino
}

Na profissão docente é necessário planejar, conforme expõe Vasconcellos:

\begin{abstract}
O planejamento enquanto construção-transformação de representações é uma mediação teórica metodológica para ação, que em função de tal mediação passa a ser consciente e intencional. Tem por finalidade procurar fazer algo vir à tona, fazer acontecer, concretizar, e para isto é necessário estabelecer as condições objetivas e subjetivas prevendo o desenvolvimento da ação no tempo. (VASCONCELLOS, 2009, p. 79)
\end{abstract}

Essa atividade exige do educador uma capacidade de repensar suas aulas. Sendo assim, esse planejar deve contemplar o currículo de maneira interdisciplinar, na perspectiva de uma alfabetização científica e na emancipação dos sujeitos envolvidos nos processos de ensino e de aprendizagem. O paradoxo criado seria o de que os professores de certa forma negligenciam o planejamento, deixando-o para segundo plano nesse processo. Nas palavras de Moretto (2007, p.100), "[...] o planejamento no contexto escolar não parece ter a importância que deveria ter".

$\mathrm{O}$ ato de planejar, enquanto atividade docente, de maneira consciente, deve ter sempre claro seu objetivo: o de estimular verdadeiros saltos quânticos no conhecimento do sujeito envolvido no processo. Deve-se organizar as ações da prática docente de modo a contribuir para alcançar a reconstrução de seu conhecimento. Se o objetivo do educador for auxiliar a tornar o educando um ser crítico à sociedade em que vive, o caminho traçado deve ter um caráter dialógico, onde pensamentos e ações de educando e educador devem assumir responsabilidade no processo. Não possuindo esse caráter, o planejamento terá no sujeito apenas mais um reprodutor da realidade, e não seu construtor. Logicamente que a formação do professor tem forte ligação com seu planejamento, que pode ser de tradição bancária, já definida por Freire (2013), ou progressista, investigativa e reconstrutiva.

Em acordo com Tardif e Lessard (2012, p.227), concorda-se sobre a importância de considerar o saber, o saber - teórico, bem como as diferentes competências e as habilidades que fundamentam o trabalho docente. Portanto, para isto é necessário formar profissionais competentes e que atuem como mediadores em sala de aula, valorizando o saber escolar de maneira a valorizar o saber dos alunos e os conhecimentos existentes, possibilitando um ensino horizontal, por meio de diálogo.

Ao planejar suas aulas o educador deve levar em consideração que todos possuem algum tipo de conhecimento, e que a posição do professor como único que sabe pode prejudicar a relação de diálogo com seus alunos. Antes disso, deveria pôr-se em posição de quem não sabe tudo (GADOTTI, 1999). Nesse sentido, a valorização do conhecimento que os alunos trazem deve estar na mente do professor ao planejar suas aulas, na tentativa de criar situações inovadoras de interação entre professor-aluno e aluno-professor.

Consciente ao planejar, o professor tem amparo nos PCN das diversas áreas, que se interligam na tentativa de apontar caminhos para "[...] a formação contínua de um professor como um profissional da educação com destaque para o além do domínio técnico e metodológico, com uma formação reflexiva e crítica. Sendo essa vista como um investimento feito no professor com reflexos nas condições de trabalho" (BRASIL, 1997, p.25).

No que diz respeito à formação inicial do professor, deve-se levar em consideração a aquisição de certos conhecimentos e competências que o tornarão um professor capacitado por meio do que se pode chamar de profissionalidade, de onde consequentemente emergiria o seu 
profissionalismo (LIBÂNEO, 2004). Dessa perspectiva, o museu interativo poderia contribuir para a aquisição de requisitos da profissionalização do professor.

Obviamente, a simples troca da sala de aula pelo espaço do museu, ou a tentativa de escolarizar o museu sem explorar seu potencial educativo (LOPES, 1991), não resultaria numa perspectiva de mudança na forma do professor.

\subsection{A pesquisa no ensino como prática inovadora}

Não se pode falar em MCT/PUCRS e seus experimentos sem citar a pesquisa como prática pedagógica. A pesquisa deve ser usada como modo de ensino e aprendizagem, oportunizando a construção do conhecimento e inovando na formação de professores. Portanto, se concorda com as palavras de Freire (1996, p. 29), quando afirma que "Não existe ensino sem pesquisa, nem pesquisa sem ensino".

A pesquisa em sala de aula precisa ser vivenciada pelos alunos e professores. Para isso é necessário que o educador saiba fazer pesquisa. Portanto, é sugerido que se formule o currículo dos futuros profissionais da educação por meio de uma proposta para esta prática docente. Pimenta (2001) propõe

[...] uma formação baseada na valorização da prática profissional como momento de construção do conhecimento, sendo que ele se dá por um processo de reflexão na ação e depois de uma reflexão sobre a reflexão na ação, abrindo perspectiva para valorização da pesquisa. (PIMENTA, 2001, p.20)

Nesse contexto, o autor propõe o museu interativo como um espaço para valorizar a prática de pesquisa, oportunizando a construção do conhecimento por meio das observações, experimentos vivenciados e, também, pela interação entre museu e escola.

É condição fatal da educação pela pesquisa que o professor seja pesquisador. Mais que isto, seja definido principalmente pela pesquisa. Não precisa ser um profissional da pesquisa, como seria o doutor que apenas ou sobretudo produz pesquisa específica. Mas precisa ser, como profissional da educação, um pesquisador. (DEMO, 2011, p. 47)

Essa interação que ocorre entre museu e escola é vivenciada tanto por alunos quanto por professores, acarretando em um ensino horizontal, por meio do qual se abre espaço para o diálogo que favorece ao aluno expressar suas dúvidas e pensamentos. Nesse sentido, essa vivência colabora com a Pesquisa no Ensino Básico.

O papel do professor, nessa troca, é o de mediador. Ele facilita e orienta as atividades, deixando assim com que o aluno tenha seus próprios pensamentos. $\mathrm{O}$ aluno deve pensar e interagir independente do professor no museu, pois assim é possível fazer com que as respostas para as dúvidas cheguem até o aluno de maneira intrínseca e automática. Porém, essa proposta deve ser muito bem planejada pelo docente. De acordo com Aebli $(1982$, p.3) "[...] quanto mais independente for a atividade do aluno, tanto mais difícil será o planejamento pelo professor."

\subsection{A interdisciplinaridade na formação docente}

Com as mudanças que estão ocorrendo ao longo dos primeiros anos do século XXI no ensino, o docente se vê na necessidade de mudar suas práticas educacionais, concepções e 
atitudes frente à demanda escolar. A primeira mudança dentro desse contexto é saber trabalhar de maneira integrada com uma ou mais áreas do conhecimento, ou seja, interdisplinarmente. Para que ocorra essa mudança o educador deve aprender a reconstruir o seu próprio conhecimento pedagógico, buscando valorizar todas as disciplinas do currículo em prol de um denominador comum.

A formação do professor, por sua vez, deve incluir conhecimentos sobre práticas interdisciplinares, contribuindo para a reconstrução do conhecimento pedagógico e didático, e também auxiliando no saber interdisciplinar. Essa prática inovadora possibilita ao educador se utilizar das diversas abordagens educativas, relacionando-as com outras áreas do saber, desenvolvendo assim, atividades interdisciplinares. Conforme Pimenta (2001), em atividades com acadêmicos de diferentes cursos de licenciatura, em situações em que, pela primeira vez, trabalham coletivamente enfrentando o desafio de conviver com diferentes linguagens e saberes, se constatou que a experiência contextualizada é essencial para que o futuro professor possa trabalhar interdisciplinarmente na escola.

Quando um ensino é traçado de forma interdisciplinar, possibilita ao aluno em formação um olhar contextualizado, articulado e global do conhecimento disciplinar. Desta maneira, ao trabalhar a prática interdisciplinar é fundamental que haja apoio nas disciplinas do conhecimento, pois a interdisciplinaridade não anula a importância da disciplina.

\begin{abstract}
A abordagem interdisciplinar atende a esta demanda, sem anular a importância da disciplinaridade do conhecimento. De toda forma, convém não esquecer que, para que haja interdisciplinaridade, é preciso que haja disciplinas. As propostas interdisciplinares surgem e desenvolvem-se apoiando-se nas disciplinas; a própria riqueza da interdisciplinaridade depende do grau de desenvolvimento atingido pelas disciplinas e estas, por sua vez, serão afetadas positivamente pelos seus contatos e colaborações interdisciplinares. (SANTOMÉ, 1998, p.61)
\end{abstract}

Conclui-se, assim, que a interdisciplinaridade permite reunir os saberes disciplinares em saberes interdisciplinares. Onde cada área do conhecimento preserva e respeita seus interesses próprios, interligando-os com novos saberes. Ocorre uma reorganização das áreas do conhecimento e uma reformulação na prática pedagógica do educador. Nesse caso, a interdisciplinaridade se torna um desafio para educadores e futuros professores. Portanto, é imprescindível que se introduza no currículo dos educadores o ensino interdisciplinar, sem desvalorizar o ensino disciplinar das diferentes áreas do conhecimento, como já justificado anteriormente.

É preciso motivar os alunos-professores para que se sintam desafiados a querer aprender, para terem desejo de ensinar. $O$ ensino pela interdisciplinaridade é um grande passo para a inovação educacional, propiciando um ensino e uma aprendizagem emancipatórios.

\title{
3 METODOLOGIA
}

Para a realização desta pesquisa foi realizado um levantamento prévio, na aula de Didática das Ciências, com as normalistas do 3o semestre noturno de uma escola pública do estado do Rio Grande do Sul. As futuras professoras foram indagadas oralmente pelo professor sobre suas percepções sobre como se planejam aulas de Ciências para alunos dos anos iniciais. Esses dados 
foram listados na lousa, conforme as estudantes iam relatando como era sua forma de elaborar planos de aula. Quais eram os métodos, quais as referências utilizadas, fontes de busca, etc.

Foi, então, proposta às estudantes uma visita orientada ao MCT/PUCRS. As alunas receberam uma lista de experimentos que estavam no museu para que elas escolhessem um conteúdo dos planos de estudo que futuramente utilizariam na elaboração de suas aulas. Realizada a visita, cada normalista planejou uma aula a partir da experiência no museu. Esses planejamentos foram compartilhados em aula, e novamente as estudantes foram inquiridas sobre suas concepções sobre como planejam aulas de Ciências no ensino fundamental, anos iniciais.

Ao realizar Análise Fenomenológica Hermenêutica (AFH), justificada pela teoria de Medeiros (2016), aplicada sobre as respostas das alunas, verificou-se em suas escritas uma forte presença das ideias de prática pedagógica, interdisciplinaridade e espaços não formais de educação. Além disso, foi visível o entusiasmo das estudantes com as possibilidades ilimitadas que as interatividades do MCT/PUCRS oferecem para o aprendizado das ciências, especialmente dos anos iniciais.

\section{RESULTADOS E DISCUSSÕES}

\subsection{A Pesquisa na Sala de Aula}

Das oito respostas analisadas referentes à pergunta "Na sua concepção, como você imagina uma educação ideal em Ciências?", todas tiveram em seus escritos referências a princípios educativos fundamentados na pesquisa em sala de aula, como fica explícito na escrita da participante B: "[...] faz o aluno questionar, evidenciar o conteúdo [...]", a palavra chave que nos possibilita ligação com a prática da pesquisa em sala de aula é o questionamento que, segundo Galiazzi, Moraes e Ramos (2012), é o primeiro princípio a ser seguido.

Já a participante D diz "Imagino uma educação ideal em Ciências, aquela voltada para nossa realidade, que integre o cotidiano dentro do conteúdo. Como por exemplo, em nossa cidade, a pedra ágata. Bem como outros fenômenos a serem explorados em sala de aula." Nesta frase vêse que a participante entende que a pesquisa deve estar inserida na sala de aula, explorando fenômenos que ocorrem no meio onde este aluno vive, ou seja, em uma aula contextualizada, partindo do interesse do aluno.

Se a pesquisa em sala de aula implica valorização do aluno e de sua produção, da mesma forma o professor deve estar em constante questionamento crítico sobre sua prática pedagógica, ou seja, adquire um perfil docente reflexivo, em que reflete sobre suas aulas e seus conhecimentos (GALIAZZI; MORAES, 2002). Isso favorece a reconstrução de seus conhecimentos e mudanças de atitudes a partir das situações problemáticas apresentadas na sala de aula.

Por outro lado, há diversos professores que somente dão aulas, reproduzindo o que thes foi ensinado, sendo incapazes de esforços individuais reconstrutivos e valorizando o mero saber repassado. Isso desvaloriza a criatividade, a reconstrução do conhecimento, o diálogo e o questionamento. A visita ao MCT/PUCRS, nesta investigação, por exemplo, foi um esforço a mais para restaurar as boas experiências discentes anteriores dessas futuras educadoras, auxiliando na estruturação de suas ações profissionais seguintes. Apesar disso, é necessário que haja relação entre a teoria e a prática, considerada hoje intrínseca ao conhecimento. Teorizar a prática passa a ser necessidade curricular, renovando-a e reconstruindo-a, pois para que ocorra uma reforma no 
ensino, segundo Morin (2000), é necessário que antes ocorra nos educadores um reaprender a pensar, reformando seu próprio pensamento.

\subsection{Práticas pedagógicas interdisciplinares}

De acordo com a resposta a uma das questões do questionário pós-visita, sobre espaço não formal de educação, verifica-se que há o desenvolvimento de uma prática pedagógica interdisciplinar, pois se nota que a participante mostra antever a união de diversas disciplinas, como se pode notar em sua fala: "Contribuem em várias situações e conteúdos. Como meio ambiente, as fases da água, com dobraduras pode ser trabalhado matemática como também pode ser utilizada em tantos outros componentes curriculares, como ciências, geografia e vários outros que podem e certamente vão nos auxiliar futuramente" (PARTICIPANTE C).

Neste sentido, verifica-se que o objetivo subjacente à investigação foi alcançado, por estar presente nas falas, como também nos trabalhos apresentados, uma prática pedagógica interdisciplinar, possibilitando que a futura professora estabeleça um olhar contextualizado, articulado e global do conhecimento disciplinar. O trabalho no MCT/PUCRS viabilizou esta prática, facilitando a percepção das educadoras em formação sobre a importância de trabalhar de forma interdisciplinar.

Os questionários aplicados às participantes possibilitaram também a emersão de ideias a partir da reflexão sobre a prática pedagógica, e isso gerou um olhar crítico sobre suas próprias práticas, contribuindo para a reconstrução dos seus saberes docentes, evoluindo seus pensamentos na direção de uma aula inovadora e reconstrutiva.

\subsection{Espaços não formais de educação como formadores das futuras professoras}

Considerou-se aqui o MCT/PUCRS como espaço não formal de ensino, sendo esta expressão usada pelos profissionais de várias áreas do conhecimento. Compreendeu-se, portanto, que o espaço formal de ensino é o espaço dentro da instituição de ensino escolar formal, e o espaço não formal de ensino é o espaço fora da instituição escolar. Ou seja, espaço formal é o espaço escolar, e o espaço não formal é qualquer outro, fora da escola.

O espaço não formal utilizado nesta investigação contribuiu para a formação das futuras professoras, auxiliando sua preparação para dar voz às tendências educacionais dos novos tempos. O MCT/PUCRS possibilitou a irradiação do conhecimento, informação e aprendizagem, integrando, assim, universidade e escola, aluno e professor e, conhecimento e informação, promovendo uma melhoria na educação e na práxis pedagógica dessas alunas e futuras professoras. Como é possível notar na fala de uma das alunas entrevistadas: "[...] contribui $e$ muito, a partir das ideias e inovações para planejamento de uma aula ampla. Buscando trabalhar vários conceitos em um único conteúdo. Pois sempre é bom estarmos correndo atrás do novo, do diferente" (PARTICIPANTE F).

O MCT/PUCRS contribuiu para o enriquecimento profissional e pessoal das participantes, de modo que esse tipo de vínculo curricular com espaços não formais de ensino deveria ser implantado no currículo formativo integrado de professores dos anos iniciais, bem como em suas 
formações continuadas, buscando, assim, a formação de um professor autônomo, que "[...] saiba desenvolver seu projeto pedagógico próprio" (GESSINGER, 2012, p.145).

Nas diversas respostas dos alunos se pode verificar que a visita ao Museu viabilizou o trabalho da professora, como é verificado na fala a seguir da Participante D: "De várias maneiras, você pode começar com uma aula de ciências, levar um vídeo explicando como funciona, para que serve, e como podemos utilizar ou até mesmo se cuidar, e pode, através do texto, fazer uma interpretação, retirar palavras acentuadas (português) e em matemática utilizando como peça chave o nome do experimento, como o da aranha visto no museu."

Disso se conclui que o MCT/PUCRS, sendo um espaço não formal de aprendizagem, pode ser utilizado de diversas formas, como no contexto de unidades didáticas, em clube de ciências, na formação continuada, na alfabetização científica, etc. Essa atividade promove a reeducação de professores e alunos, melhorando, assim, a eficácia dos sistema de ensino e da educação continuada de professores, contribuindo para a formação de cidadãos capazes de compreender a Ciência e a tecnologia do mundo onde estão inseridos, tendo a pesquisa como base de seu fazer pedagógico.

\section{CONCLUSÃO}

Após a realização da visita emergiram novas concepções sobre o planejamento de aulas, trazendo uma visão de caráter interdisciplinar. Viu-se que as futuras professoras não possuíam em sua formação a percepção sobre como utilizar espaços não formais de educação em seus planejamentos. Por meio da visita orientada pelos pesquisadores ao museu interativo da PUCRS, os alunos refletiram sobre práticas pedagógicas inovadoras e elaboração de planos de aulas, valorizando, em graus diferentes de intensidade, os espaços não formais de educação, assim como a visão interdisciplinar.

A pesquisa aponta para um avanço significativo no que se refere à formação das futuras professoras, apontado e descrito nas falas recolhidas antes e depois da visita. Observou-se, também, que as participantes da pesquisa transformaram suas percepções sobre 0 ato de planejar. Inicialmente, notou-se um discurso de caráter disciplinar que, ao longo da pesquisa, foi se transformando em caráter interdisciplinar, possibilitando, assim, uma evolução de suas reflexões sobre suas práticas educacionais, a partir do uso de espaços não formais de educação.

Tais transformações permitiram a reconstrução de suas visões de ensino. Antes da visita as futuras professoras não viam possibilidade de proporem qualquer atividade que fosse além de uma aula transmissiva, descontextualizada e fragmentada. Agora, seus discursos já incluem a possibilidade de realização de atividades interativas e contextualizadas. Por meio dessa segunda visão, o aluno vai se tornando o centro e o objetivo do ensino, passando a interagir com os novos conhecimentos de maneira interdisciplinar, diferentemente da velha prática apoiada somente no livro didático.

Nas diversas respostas das alunas foi possível verificar que o MCT/PUCRS viabiliza um trabalho de utilidade aos professores, sendo fonte de experimentos diversos, provocadores de várias possibilidades pedagógicas, desde uma simples produção de texto até a ideia de reconstruir seus próprios conhecimentos. 
Os princípios da pesquisa em sala de aula estão presentes nas respostas encontradas nesta investigação, assim como o caráter interdisciplinar. Logo, o uso de espaços não formais de aprendizagem promove a aprendizagem de maneira participativa, dialogada, contextualizada, argumentativa, vivenciada, interessante, interativa e questionadora. Tais características foram indicadas nas respostas das mesmas entrevistadas como sendo de uma aula ideal de Ciências. Mesmo sabendo que o ideal é inalcançável, o caminho em sua direção passa pela pesquisa, pela inovação e pela interdisciplinaridade.

\section{REFERÊNCIAS}

Aebli, H. (1982). Prática de Ensino: formas fundamentais de ensino elementar, médio e superior.

(tradução de Edwino Aluysius Royer). São Paulo: EDUSP.

Bianconi, M. L., CARUSO, F. (2005). Educação não-formal. Cienc. Cult., v.57, n.4, p.20, dez. Disponível em: http://cienciaecultura.bvs.br/cgi-bin/wxis.exe/iah/. Acesso em 27/04/2016.

Brasil. (1997). Secretaria De Educação Fundamental. Parâmetros Curriculares Nacionais: introdução aos Parâmetros Curriculares Nacionais / Secretaria de Educação Fundamental. Brasília: MEC/SEF, 126p.

Brasil. ECA - Estatuto da Criança e Adolescente. Disponível em: http://www.planalto.gov.br/ccivil_03/leis/L8069.htm. Acesso em 23/07/2016.

Brasil. Ministério Da Educação. (2009). Salto para o Futuro: museu e escola: a educação formal e não formal, Ano XIX - № 3 - Maio, Rio de Janeiro. Acessado em 25/05/2016.

Castro, A. L. S. (2007). Memórias clandestinas e sua museificação. Rio de Janeiro: Revan, 212p.

Chassot, A. (2003). Alfabetização Científica: uma possibilidade para a inclusão social. Revista Brasileira de Educação. III Cumbre Iberoamericano de Rectores de Universidades Públicas. São Paulo, n. 22, p.89-100.

Demo, P. (2011). Educar pela Pesquisa. Campinas: Autores Associados. 9. Ed.

Freire, P. (2013). Pedagogia do oprimido. São Paulo: Paz e Terra. 50. Ed. - (1996). Pedagogia da autonomia: saberes necessários à prática educativa. São Paulo: Paz e Terra 25. Ed.

Gadotti, M. (1999). Convite à leitura de Paulo Freire. São Paulo: Scipione.

Galiazzi, M. C., Moraes, R. (2002). Educação pela pesquisa como modo, tempo e espaço de qualificação da formação de professores de ciências. Ciência \& Educação, Bauru, v.8, n.2, p. 237-252. Disponível em: http://www.scielo.br/scielo.php?pid=S1516$73132002000200008 \&$ script=sci_arttext\&tIng=pt. Acesso em 12/07/2016.

Galiazzi, M. C., Moraes, R., Ramos, M. G. (2012). Pesquisa em sala de aula: fundamentos e pressupostos. In: Pesquisa em sala de aula: tendências para a educação em novos tempos. In: MORAES, R. et. Al. (Org.) 3. Ed. Porto Alegre: EDIPUCRS, p. 11-20.

Internacional Concil Of Museums (ICOM). (2007). Disponível em: http://icom.museum/thevision/museum-definition/. Acesso em 12/05/2016.

Lara, I. C. M., Velho, E. M. (2013). Museu interativo e a sala de aula: Uma proposta Interdisciplinar na área das Ciências Naturais, Matemática e seus Tecnologias. Caderno Pedagógico, Lajeado, v.10, n.1, p. 41-59. Disponível em:

http://univates.br/revistas/index.php/cadped/article/view/870. Acesso em 11/05/2016.

Libâneo, J. C. (2004). Organização e gestão da escola: teoria e prática. 5. Ed. Goiânia: Alternativa. Lopes, M. M. (1991). A favor da desescolorização dos museus. Revista Educação Sociedade.

Campinas, v.3, n. 40, dezembro. 
Medeiros, G. S. (2016). Olhar para o Sol: concepção da Análise Fenomenológica Hermenêutica. 2016. Dissertação de Mestrado. Pontifícia Universidade Católica do Rio Grande do Sul. Porto Alegre.

Moretto, V. P. (2007). Planejamento: planejando a educação para o desenvolvimento de competências. Petrópolis: Vozes.

Piedade Filho, L. F. R. (2009). Museu, Ciência, Tecnologia e Sociedade: o museu enquanto espaço de difusão e divulgação científica. Foro Ibero-Americano de Comunicação e Divulgação Científica, Campinas, UNICAMP. Anais... Disponível em: http://WWW.oie.es/forocampinas/PDF_ACTAS/COMUNICACIONES/grupo3/070.pdf. Acesso em 13/05/2015.

Pimenta, S. G. (2001). Formação de professores: saberes da docência e identidade do professor. In: Fazenda, I. C. A. (Org.). Didática e interdisciplinaridade. 5. Ed. Campinas: Papirus.

Santomé, J. T. (1998). Globalização e interdisciplinaridade: o currículo integrado. Porto Alegre: Artmed.

Tardif, M., Lessard, C. (2012). O Trabalho Docente: elementos para uma teoria da docência como profissão de interações humanas. Petropólis: Vozes.

Vasconcellos, C. S. (2009). Planejamento Projeto de Ensino-Aprendizagem e Projeto PolíticoPedagógico. Ladermos Libertad-1. 7. Ed. São Paulo. 